\title{
Cardiogenic shock in ACS. Part 2: role of mechanical circulatory support
}

\author{
Stephen Westaby, Kyriakos Anastasiadis and George M. Wieselthaler
}

\begin{abstract}
This Review explores contemporary circulatory support in profound postinfarction cardiogenic shock. Frequently, death is the only alternative to implantation of a blood pump, so prospective randomized trials of device versus medical treatment are unacceptable and evidence is derived from clinical experience. Irrespective of ACC/AHA and European guidelines, no study has shown survival benefit for the intra-aortic balloon pump in patients with established shock. In the past 10 years, the safety and durability of mechanical blood pumps has improved considerably. New temporary and long-term rotary pumps have transformed outcomes for patients with acute heart failure. For urgent resuscitation, outreach salvage, and transportation extracorporeal membrane oxygenation (ECMO) is a reliable, but time limited, first step. ECMO decompresses the venous system, provides flow, and ensures oxygenation, but does not unload the failing left ventricle. Myocardial stunning takes days, and sometimes weeks, to recover. Effective ventricular unloading is best achieved by surgical implantation of a temporary rotary or volume-displacement pump. After cardiopulmonary resuscitation, hemodynamic stabilization allows assessment of cerebral injury and prognosis. Published series demonstrate that $50-75 \%$ of patients with profound shock can be salvaged either through native heart recovery, urgent transplantation, or switch to a long-term pump.
\end{abstract}

Westaby, S. et al. Nat. Rev. Cardiol. 9, 195-208 (2012); published online 10 January 2012; doi:10.1038/nrcardio.2011.205

\section{Introduction}

In profound cardiogenic shock, blood flow and perfusion pressure must be restored urgently to prevent permanent damage to the brain, liver, kidneys, and gut. Adequate right ventricular function is necessary to avoid central venous hypertension and end-organ venous congestion. ${ }^{1}$ In mechanical engineering, a failing pump is repaired or replaced provided that the rest of the system remains in working order. The same strategy can be applied in patients with heart failure using modern circulatory support technology. The landmark REMATCH study ${ }^{2}$ established a long-term role for left ventricular assist devices (LVADs) to relieve symptoms and improve longevity in terminally ill patients with cardiomyopathy who were not eligible for a heart transplant. ${ }^{2}$ In acute refractory postinfarction shock, however, death is the only alternative to implantation of a blood pump; therefore, wellpowered randomized trials are unlikely to be conducted. ${ }^{3}$ Evidence for the use of these devices in cardiogenic shock must, therefore, be derived from clinical experience where a substantial number of survivors signifies positive outcome.

The rationale for left ventricular unloading is straightforward. The failing heart beats more than 120,000 times

\section{Competing interests}

S. Westaby declares an association with the following company: Calon Cardio-Technology. G. M. Wieselthaler declares an association with the following company: HeartWare. See the article online for full details of the relationships. K. Anastasiadis declares no competing interests. per day and pumps 7,000l of blood against raised afterload. A dilated heart has elevated wall tension, impaired subendocardial blood flow, and increased oxygen consumption. Adrenergic inotropes further increase heart rate, afterload, and wall tension whereas an LVAD unloads the heart, while boosting coronary and systemic blood flow. Left ventricular unloading promotes both myocardial and end-organ recovery. Inexpensive, short-term systems can sustain the reperfused patient over days or weeks after a myocardial infarction, until ischemic stunning resolves. For irreversible injury, the same blood pumps can sustain life pending cardiac transplantation or implantation of a long-term LVAD. ${ }^{4}$ Over the past 10 years, the safety and reliability of LVADs has improved considerably, whereas the efficacy of the intra-aortic balloon pump (IABP) has been questioned. ${ }^{5}$

Currently, very few patients have access to advanced life support, even after early and effective primary percutaneous coronary intervention (PPCI). Those with recoverable postischemic dysfunction may die unnecessarily from cardiogenic shock, thus maintaining the persistent excessive mortality associated with this condition. ${ }^{6}$ Systems of care have failed to keep pace with advances in technology. In the second part of our Review on cardiogenic shock in acute coronary syndromes, we explore contemporary circulatory support strategies for use after myocardial infarction and prospects for the future of these therapeutic options. We also address the moral question as to whether patients with acute cardiac failure should expect similar
Department of

Cardiothoracic Surgery,

John Radcliffe Hospital,

Headley Way,

Headington,

Oxford OX3 9DU, UK

(S. Westaby). AHEPA

University Hospital,

St. Kyriakidis 1,

Thessaloniki 54636 ,

Greece

(K. Anastasiadis).

Division of

Cardiothoracic Surgery,

Department of Surgery,

University of California,

San Francisco, 500

Parnassus Avenue,

San Francisco,

CA 94143-0118, USA

(G. M. Wieselthaler).

Correspondence to:

S. Westaby

swestaby@ahf.org.uk 


\section{Key points}

- Evidence for the survival benefit associated with circulatory assist devices in patients with acute refractory postinfarction cardiogenic shock comes from observational studies or device comparisons

- Irrespective of clinical guidelines, the intra-aortic balloon pump does not significantly improve cardiac output in patients with shock and no clinical trial has shown survival benefit with this device

- Although the duration of support with extra corporeal membrane oxygenation is limited to days, it can be deployed rapidly without imaging, even during cardiopulmonary resuscitation

- The percutaneous devices Impella Recover ${ }^{\circledR}$ (Abiomed, Aachen, Germany) and TandemHeart ${ }^{\circledR}$ (CardiacAssist, Inc., Pittsburgh, PA, USA) boost systemic blood flow, but have not demonstrated survival benefit in established shock

- Surgically implanted blood pumps can sustain systemic or pulmonary blood flow at physiological levels for weeks or months pending functional recovery, use of a permanent assist device, or transplantation

- Although the safety and durability of blood pumps is improving, access to treatment remains limited and subject to geographic and demographic variables

levels of intervention as those with renal impairment for whom dialysis is performed routinely irrespective of age. ${ }^{7}$

\section{The intra-aortic balloon pump}

Introduced in the 1960s, the IABP is inserted into the descending aorta between the arch vessels and renal arteries (Figure 1a). ${ }^{8}$ The balloon $(34 \mathrm{ml}$ or $40 \mathrm{ml}$ ) inflates immediately after left ventricular ejection and is deflated before the onset of the following systole. ${ }^{9}$ Accurate timing is essential for optimum performance. When the balloon inflates, it displaces blood upstream towards the heart, thereby increasing early diastolic pressure. When deflated, the balloon draws blood volume downstream, reducing end-diastolic pressure and left ventricular afterload. Other beneficial effects are a decrease in left ventricular volume, systolic work, and myocardial oxygen consumption together with reduced end-diastolic and peak-systolic aortic pressure. ${ }^{9}$ A clinical study showed only a small fraction of the balloon volume (6.4\% during 1:1 inflation and $10.0 \%$ with 1:2 support) reached the aortic root. ${ }^{9}$ The rest of the retrogradely displaced balloon volume was distributed between the arch branches or stored within a compliant proximal aorta providing no clinical benefit. ${ }^{9}$ In humans with healthy coronary vessels, a mean coronary flow of $200 \mathrm{ml} / \mathrm{min}$, and heart rate of $75 \mathrm{bpm}$, balloon inflation provides an extra flow of $2.5 \mathrm{ml}$ of blood to the coronary circulation per heart cycle. ${ }^{9}$ For a heart of average weight $(300 \mathrm{~g})$, coronary perfusion would be $2.75 \mathrm{ml}$ per beat without IABP support and $3.25 \mathrm{ml}$ per beat with IABP support.

Given the ease of percutaneous implantation, as well as its acceptable cost and low complication rate, the IABP stands as the only form of mechanical assistance available in most cardiac and general intensive care units. Approximately 70,000 IABPs are used annually in the USA, $20 \%$ of which are deployed for cardiogenic shock. ${ }^{10}$ The IABP has gained a class $1 \mathrm{C}$ recommendation for use in cardiogenic shock by the European Society for Cardio$\log { }^{11}$ and class $1 \mathrm{~B}$ recommendation in the ACC/AHA guidelines, ${ }^{12}$ although these recommendations were made on the basis of data from nonrandomized studies.
According to the 1999 Task Force on Practice Guidelines of the ACC/AHA, ${ }^{12}$ class 1 indications for IABP use in acute myocardial infarction include, first, as a stabilizing measure for angiography and prompt revascularization; second, for acute mitral regurgitation or ventricular septal rupture; third, for recurrent intractable ventricular arrhythmias with hemodynamic instability and; fourth, for refractory postinfarction angina. ${ }^{12}$ Despite these recommendations, the prevalence of IABP use in cardiogenic shock related to ST-segment elevation myocardial infarction (STEMI) is low (20-39\%). ${ }^{3}$ No adequately powered controlled trials have been performed to investigate the effectiveness of this therapy. By contrast, study data challenge both the benefit of the IABP and recommendations in existing guidelines. ${ }^{8}$

The influence of the IABP on ischemic right ventricular function is much debated. Right ventricular dysfunction complicates around half of inferior wall infarctions and occurs to some degree in $20-30 \%$ of patients who receive an LVAD. A porcine model of acute ischemic right heart failure with cardiogenic shock, constructed by Nordhaug and colleagues, has clarified this issue. ${ }^{13}$ Right coronary embolization with microspheres was used to induce right ventricular infarction and hemodynamic changes were monitored with right and left ventricular pressureconductance recordings. Half of the pigs received an IABP, which had no influence on right or left ventricular contractility. However the use of an IABP resulted in significantly improved cardiac output and mean systemic arterial pressure compared with controls. These animals had lower pulmonary vascular resistance $(795 \pm 63$ versus $912 \pm 259$ dynes $\left./ \mathrm{s} / \mathrm{cm}^{-5}, P<0.01\right)$ and pulmonary arterial elastance. Right ventricular efficiency was also improved in the IABP group (stroke work per pressure-volume area $0.60 \pm 0.14$ versus $0.41 \pm 0.12, P<0.01$ ). The investigators concluded that the benefits were derived from IABP-induced reduction in pulmonary arterial resistance. ${ }^{13}$

In diseased coronary arteries, the effects of IABP on flow depends inversely on the severity of the narrowing with the potential for reduction in flow with IABP in severe stenosis. ${ }^{14}$ Transesophageal echocardiography shows that peak diastolic coronary flow velocity increases by a mean of $117 \%$ during IABP inflation, with increased mean flow velocity integral of $87 \% .{ }^{15}$ Blood flow velocities of 1.5-2.0 times that without IABP support have been recorded in the stenosed left anterior descending coronary artery. ${ }^{16}$ The IABP does not substantially increase systemic blood flow $\left(<500 \mathrm{ml} / \mathrm{min} / \mathrm{m}^{2}\right)$, only increasing flow to the coronaries, and is progressively less effective as stroke volume and blood pressure fall. ${ }^{17}$ Other factors that determine the effectiveness of this treatment include balloon volume, location in the aorta, rate of inflation, and presence of cardiac arrhythmias. An elastic aorta recoils during diastole (coinciding with balloon inflation); consequently, IABP efficiency is limited in highly compliant aortas. Leg ischemia through mechanical obstruction, thrombosis, or embolism is the predominant complication in $9-36 \%$ of patients treated with an IABP. ${ }^{18}$ Factors that predispose a patient to leg ischemia are female sex, and the presence of diabetes mellitus or peripheral 
a

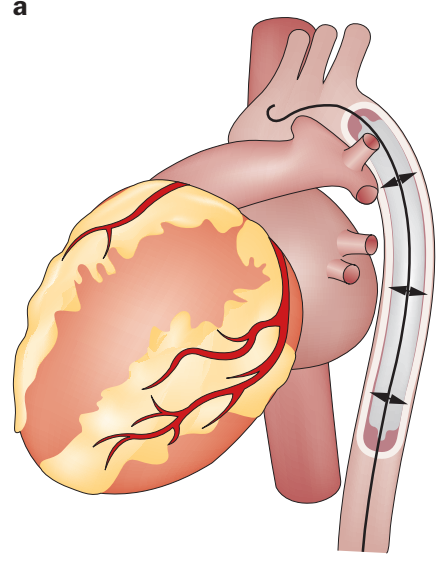

b

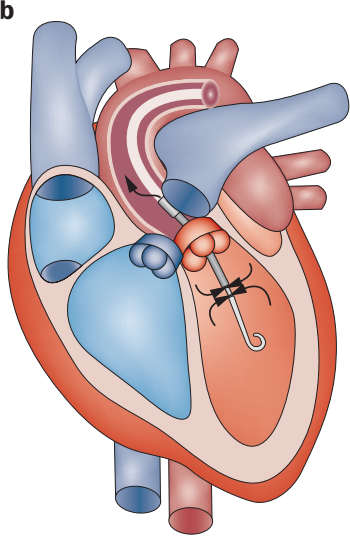

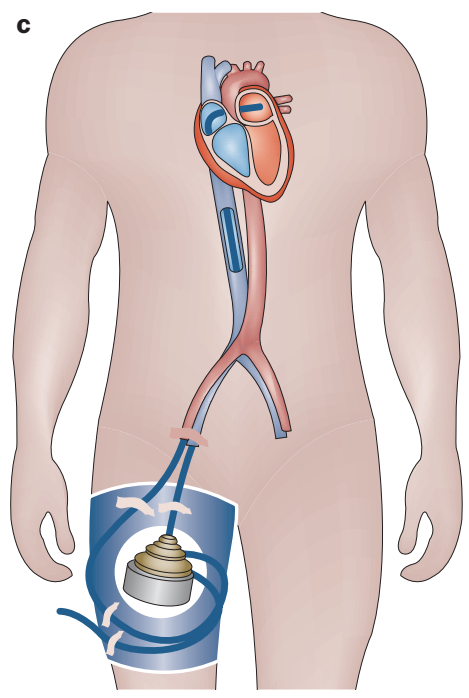

Figure 1 | Schematic representation of some mechanical circulatory support options. a | Intra-aortic balloon pump, which is inserted into the descending aorta between the arch vessels and renal arteries. b | Impella Recover ${ }^{\circledR}$ (Abiomed, Aachen, Germany). This device is percutaneously inserted via the femoral artery and positioned across the aortic valve. c | TandemHeart ${ }^{\circledR}$ (CardiacAssist, Inc., Pittsburgh, PA, USA). A cannula is inserted percutaneously through the right femoral vein and advanced towards the right atrium, where it is introduced by transatrial septal perforation. A cannula in either femoral artery then provides left heart bypass. Modified from Desai, N. R. \& Bhatt, D. L. Evaluating percutaneous support for cardiogenic shock: data shock and sticker shock. Eur. Heart J., 2009, 30, 2073-2075, by permission of Oxford University Press and the European Society of Cardiology.

vascular disease. In addition, the IABP can cause mesenteric ischemia or pancreatitis through atheroemboli in the celiac access. ${ }^{17}$

Observational data from the SHOCK trial registry, ${ }^{19}$ as well as the US NRMI- $2^{20}$ suggest that patients who received an IABP in addition to thrombolysis had lower in-hospital mortality than those receiving thrombolysis alone, whereas those undergoing PPCI in NRMI-2 had no benefit from the IABP. Sjauw et al. performed two comprehensive meta-analyses of randomized trials of IABP use in high-risk patients with STEMI, with and without cardiogenic shock..$^{21}$ The first included 1,009 patients in seven randomized trials of STEMI without shock and demonstrated no 30-day survival benefit or improvement in left ventricular ejection fraction (LVEF), but a substantial increase in stroke and bleeding rates. The second metaanalysis included nine studies and a total of 10,529 patients with postinfarction cardiogenic shock. Paradoxically, those treated with PPCI and an IABP had a $6 \%$ increase in 30-day mortality, which contrasted with a significant $18 \%$ decrease in 30-day mortality for those undergoing thrombolysis and IABP therapy. ${ }^{21}$ This finding was mainly influenced by data from NRMI-2, in which IABP therapy was independently associated with increased 30-day mortality after multivariate adjustment for age, clinical risk factors, PPCI, and CABG surgery. The apparent negative effect of the IABP could reflect an increase in the duration of myocardial ischemia, because an IABP was used during transfer to a PPCI center. Sjauw et al. concluded that the IABP only provided survival benefit in patients with shock as an adjunct to thrombolysis. The findings did not support the concept that the IABP is beneficial independent of the type of reperfusion therapy. ${ }^{21}$ In turn, the thrombolysis effect could be explained by bias because the studies included in the meta-analysis predominantly involved patients who received anIABP rather than either thrombolysis or PPCI alone. The apparently detrimental effect of the IABP as an adjunct to PPCI in STEMI cardiogenic shock is intriguing and contradicts the suggestion that underutilization of IABP therapy could account for persistently high mortality in studies of patients with shock. In contrast to the results of these meta-analyses, Ohman and Hochman reviewed data from 182 patients who underwent PPCI within $24 \mathrm{~h}$ of infarction and found IABP therapy to be associated with a significant reduction in the rate of coronary reocclusion ( $8 \%$ versus $21 \%$ ) together with other complications, such as reinfarction, stroke, or recurrent ischemia ( $13 \%$ versus $24 \%, P<0.05) .{ }^{22}$

In studies of the comparison between the use of IABP and percutaneous LVADs, detailed hemodynamic measurements confirmed that the IABP effect is not sufficient to sustain life. ${ }^{23}$ In the PAMI-2 trial, ${ }^{24}$ high-risk patients (aged $>70$ years, three-vessel disease, LVEF $<45 \%$, suboptimal angioplasty result, or vein-graft occlusion) underwent $36-48 \mathrm{~h}$ of IABP support, but with no recordable benefit. The IABP did not influence the rate of coronary reocclusion when compared with angioplasty alone (6.7\% versus $5.5 \%)$, reinfarction (6.2\% versus $8.0 \%)$, or hospital mortality ( $4.3 \%$ versus $3.1 \%) .{ }^{24}$ A more-recent randomized study, TACTICS, ${ }^{25}$ was stopped prematurely owing to poor recruitment, but the data suggested no survival benefit from adding IABP therapy to fibrinolysis. In summary, no evidence exists for clinical benefit from the IABP in patients with established cardiogenic shock. Because of the substantial implications for existing guidelines, the investigators of the 
ongoing IABP-SHOCK-II trial ${ }^{26}$ are currently recruiting 600 patients over 2.5 years to examine 30 -day mortality with or without IABP therapy.

\section{Percutaneously implanted blood pumps}

Shock may already be apparent at the time of PPCI, or can be predicted from angiographic or echocardiographic findings. ${ }^{27-29}$ In both circumstances, two percutaneously implanted blood pumps are available to the cardiologist without the need for immediate intervention by surgeons or perfusionists-The Impella Recover ${ }^{\circledR}$ (Abiomed, Aachen, Germany) ${ }^{30}$ and TandemHeart ${ }^{\circledR}$ (CardiacAssist, Inc., Pittsburgh, PA, USA). ${ }^{31}$ These innovative LVADs are deployed in the catheterization laboratory and, when first introduced, were anticipated to prove more successful in sustaining patients with shock than the IABP. ${ }^{32}$ These devices have the capacity to improve systemic blood flow and pressure, reduce wall stress, and improve coronary flow providing a setting for functional recovery. ${ }^{33}$ Experimental and clinical evidence suggests that they could also reduce infarct size. . $^{34,35}$

The catheter-based Impella Recover ${ }^{\circledR} 2.5$ is percutaneously inserted via the femoral artery ${ }^{31}$. This device has a 12 French pump motor, which is positioned across the aortic valve using radiological screening or echocardiography (Figure 1b). The pump is connected to a $3 \mathrm{~kg}$ portable external pump console and provides flow up to $2.5 \mathrm{l} / \mathrm{min}$ by sucking blood from the left ventricular cavity and ejecting into the aorta. Again, duration of support is limited to 1 week. A larger version of the device, the Impella Recover ${ }^{\circledast} 5.0$, provides flow up to $51 / \mathrm{min}$, but requires surgical implantation either via sternotomy with direct introduction into the aorta or by using a vascular graft anastomosed by cut down onto the femoral or axillary artery. Although reliable and functionally effective, the Impella Recover ${ }^{\circledast} 2.5$ has a number of limitations including insufficient flow from the periphery in larger patients ( $>100 \mathrm{~kg}$ body weight), short duration of support, and tendency for displacement of the inflow out of the left ventricle. Patients with atherosclerosis are at risk of leg ischemia. ${ }^{36}$ Aortic stenosis, aortic regurgitation, or the presence of a mechanical aortic prosthesis, preclude the use of this system.

In a comparative clinical study, Lemarche et al. showed that the Impella Recover ${ }^{\oplus}$ device and extracorporeal membrane oxygenation (ECMO, which is discussed in the next section) had similar hemodynamic profiles (mean flow $3.7 \mathrm{l} / \mathrm{min}$ and $4.01 / \mathrm{min}$, respectively), and that the Impella Recover ${ }^{\otimes}$ had no survival advantage. ${ }^{37}$ Seyfarth and colleagues compared the efficacy of the Impella Recover $^{\circledR}$ and IABP therapy. ${ }^{38}$ The LVAD achieved better hemodynamics than IABP, but was not associated with a survival advantage. ${ }^{38}$

Also available to the cardiologist is the TandemHeart ${ }^{\circledast}$ (originally known as the AB-180)-a short-term ( $<14$ days) external centrifugal blood pump with a fluid dynamic hydraulic bearing and rotational speed of 2,500$4,500 \mathrm{rpm} .{ }^{31} \mathrm{~A}$ long 21 French inflow cannula is inserted percutaneously through the right femoral vein and advanced towards the right atrium. Under fluoroscopic and echocardiographic control, transatrial septal perforation introduces the tip of the inflow cannula into the left atrium. A 17 French cannula in either femoral artery then provides left heart bypass at a flow rate of around $41 / \mathrm{min}$ (Figure 1c). The working pump is constantly purged with heparinized saline with the patient maintained with a partial thromboplastin time of 60-80 s. Right ventricular support is possible using transjugular cannulation of the right atrium with pulmonary artery cannulation via a femoral vein.

Clinical trials in Europe of patients with cardiogenic shock confirmed the hemodynamic efficacy of the TandemHeart ${ }^{\circledast}$, but leg ischemia distal to the implantation site limited device deployment in smaller patients ( $<70 \mathrm{~kg}$ body weight). ${ }^{33}$ Thiele et al. showed that the TandemHeart ${ }^{\circledast}$ increased cardiac index from a mean of $1.7 \pm 0.31 / \mathrm{min}$ to $2.4 \pm 0.6 \mathrm{l} / \mathrm{min}$ with a rise in blood pressure from $63 \pm 8 \mathrm{mmHg}$ to $80 \pm 9 \mathrm{mmHg} .{ }^{39}$ Mean pulmonary artery pressure fell from $31 \pm 8 \mathrm{mmHg}$ to $23 \pm 6 \mathrm{mmHg}$ and pulmonary capillary wedge pressure from $21 \pm 4 \mathrm{mmHg}$ to $14 \pm 4 \mathrm{mmHg}$. However, when compared with the IABP in a randomized trial, the same investigators found no survival benefit for the TandemHeart ${ }^{\circledast} .{ }^{39}$ Moreover, in a multicenter, randomized trial, Burkhoff et al. also failed to demonstrate a benefit of the TandemHeart ${ }^{\circledR}$ over the IABP. ${ }^{31}$

The largest report of TandemHeart ${ }^{\circledR}$ use comes from the Texas Heart Institute in Houston, TX, USA. Kar and colleagues described 117 patients with otherwise fatal refractory cardiogenic shock, half of whom had undergone cardiopulmonary resuscitation. ${ }^{40} \mathrm{On}$ instigation of pump flow, mean cardiac index increased from a catastrophic $0.51 / \mathrm{min} / \mathrm{m}^{2}$ to $3.01 / \mathrm{min} / \mathrm{m}^{2}$ with a rise in systolic blood pressure from $75 \mathrm{mmHg}$ to $100 \mathrm{mmHg}$ and myocardial oxygen consumption $\left(\mathrm{MVO}_{2}\right)$ from $49 \%$ to $69 \%$. Wherever possible, pump flow was regulated to achieve $\mathrm{MVO}_{2}>70 \%$ and mean blood pressure $>60 \mathrm{mmHg}$. The device took 15-65 min to implant, with a mean duration of $65 \pm 41 \mathrm{~min}$ from cardiopulmonary resuscitation to establishing device flow. The average duration of TandemHeart ${ }^{\circledast}$ support was 6 days, and the therapy provided a remarkable $60 \% 30$-day survival. Half of the patients had STEMI, and 30-day survival among these individuals was $50 \%$, although some were rescued by urgent cardiac transplantation or bridged to a long-term LVAD. Despite the success rate, many patients suffered complications. Sepsis or a systemic inflammatory response occurred in $30 \%$ of patients after implantation, in some instances related to postinfarction cardiogenic shock; $11 \%$ experienced coagulopathy, $20 \%$ had a gastrointestinal hemorrhage, and $7 \%$ suffered a stroke. ${ }^{40}$ On occasion, displacement of the tip of the inflow cannula back into the right atrium caused profound desaturation, which can prove fatal in minutes. In comparison with the patients enrolled in the SHOCK trial, ${ }^{41}$ those in this cohort ${ }^{40}$ had a greater risk profile, with lower mean LVEF ( $23 \%$ versus $29 \%)$, cardiac index $\left(0.361 / \mathrm{min} / \mathrm{m}^{2}\right.$ versus $\left.1.81 / \mathrm{min} / \mathrm{m}^{2}\right)$, and systolic blood pressure $(71 \mathrm{mmHg}$ versus $89 \mathrm{mmHg})$.

Irrespective of numerous optimistic clinical reports, we are left with the question - do the hemodynamic effects of 
percutaneous LVADs improve outcome for patients with shock? Cheng et al. conducted a meta-analysis ${ }^{23}$ of three randomized clinical studies in patients with postinfarction shock, in which the IABP was directly compared with the TandemHeart ${ }^{\circledR}$ (two studies) or the Impella Recover ${ }^{\circledR}$ (one study). Most of the included 100 patients received full medical management, including positive pressure ventilation. In each of the individual studies, the LVAD provided greater cardiac index, mean arterial pressure, and reduced pulmonary capillary wedge pressure in comparison with the IABP, but these findings did not translate into survival benefit (pooled estimate of relative risk 1.06, 95\% CI 0.68$1.66, P=0.8)$. Survival for patients with an LVAD was $53 \%$, marginally less impressive than for the Texas Heart Center study. ${ }^{40}$ Survival among patients in the IABP groups was similar to those with an LVAD, but the IABP had a better safety profile, whereas the LVADs were ten-times more expensive. Use of the TandemHeart ${ }^{\circledR}$ led to a significantly greater incidence of limb ischemia and bleeding than IABP use. ${ }^{23}$

Although these findings were surprising for those who expected pump flow to improve survival, ultimate failure to do so has several possible explanations. Firstly duration of support was too short ( $<7$ days) for sufficient recovery from ischemia and myocardial stunning. Second, left atrial cannulation in the TandemHeart ${ }^{\circledR}$ and inadequate flow from Impella Recover ${ }^{\circledR} 2.5$ might not have effectively unloaded the failing ventricle or reduced infarct size. Third, the limited flow through peripherally inserted conduits was probably insufficient to reverse multiorgan failure, particularly for patients with systemic inflammatory response syndrome. ${ }^{42}$ Lastly, the incidence of limb ischemia was substantial with percutaneous LVADs, which in some cases necessitated early removal of the device. Although disappointing in established cardiogenic shock, percutaneous LVADs still have an important role in patients with hemodynamic instability undergoing high-risk PPCI. ${ }^{43-45}$

\section{Extracorporeal membrane oxygenation}

ECMO is used to sustain physiological levels of blood flow in cardiogenic shock, as a rescue system during cardiopulmonary resuscitation, ${ }^{46,47}$ and to provide both cardiac and pulmonary support for patients with hypoxia. An ECMO circuit consists of a centrifugal blood pump, membrane oxygenator, and a heparin-coated circuit. ECMO is the simplest and most-rapid method of restoring systemic blood flow and, with contemporary peripheral arteriovenous cannulation techniques, can now be used in the catheterization laboratory or emergency room. ${ }^{48}$ The circuit takes around $10-15 \mathrm{~min}$ for the perfusionist to assemble. Cannulation of the femoral artery and vein are achieved rapidly by the Seldinger technique, using specifically designed perfusion cannulas over a guidewire, even during cardiac massage or PPCI. The tip of the femoral arterial cannula is advanced to the aortoiliac junction and the venous drainage pipe advanced into the lower right atrium. Systemic heparinization is used to achieve an activated clotting time of $150-180$ s. Flow rates are initiated at $2-31 / \mathrm{min}$ using dopamine to raise

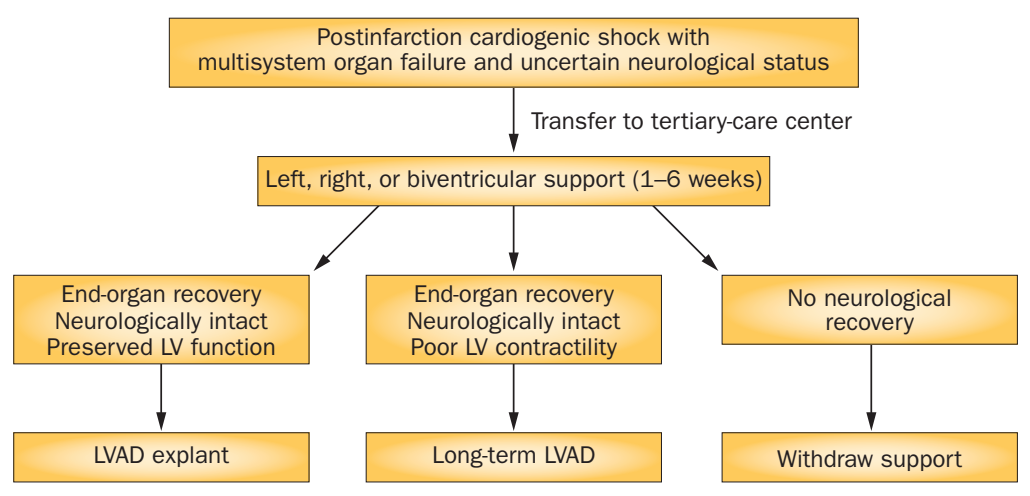

Figure 2 | Management of patients with cardiogenic shock after cardiopulmonary resuscitation. Abbreviations: LV, left ventricular; LVAD, left ventricular assist device.

mean blood pressure to $>55 \mathrm{mmHg}$. Once the circuit is established, the flow rate can be progressively increased to $3.5-4.01 / \mathrm{min}$, thus restoring a normal cardiac index and mean blood pressure to $>70 \mathrm{mmHg}$. A pulsatile arterial pressure trace confirms residual myocardial contractility and reduced risk of intracardiac clot formation. If pulsation disappears, volume expansion or inotropic support is used until pulsatility is restored. Rapid stabilization of hemodynamic status enables biochemical derangement to be corrected and allows time to determine cerebral status following cardiac arrest. The potential for myocardial recovery, cardiac transplantation, or a long-term LVAD use can then be assessed (Figure 2). Because venoarterial ECMO increases left ventricular afterload and wall stress, cardiac contractility must be maintained to avoid left ventricular distension, clot on the akinetic myocardium, or pulmonary hypertension using an IABP and inotropes. ECMO does not adequately unload the left ventricle unless a trans-septal or apical left ventricular vent is inserted. ${ }^{49}$ Major problems arise when the femoral or iliac arteries are small, kinked, or obstructed by atherosclerosis. Limb ischemia occurs in $13-30 \%$ of cases, but can be relieved with distal limb perfusion or by using a Dacron side graft to prevent arterial occlusion during cannula insertion..$^{50}$ Flow is limited by cannula size and, when body surface area exceeds $2 \mathrm{~m}^{2}, 3-41$ of flow might not be sufficient to prevent multiorgan failure. Greater flow can only be achieved by surgical intervention and central cannulation.

For patients with shock at presentation, Sheu et al. recommend ECMO to support transradial PPCI. ${ }^{51}$ In a series in which all unsupported patients died, ECMO resulted in $33 \%$ and $45.8 \%$ reductions in the absolute and relative risks of death, respectively. ${ }^{51}$ All patients underwent ECMO for at least $72 \mathrm{~h}$ and were weaned only when LVEF was $>40 \%$ and $\mathrm{MVO}_{2}>70 \%$. Oxygenation was well maintained. Final Thrombolysis In Myocardial Infarction (TIMI) grade 3 flow was notably better in patients undergoing ECMO than in a group of patients treated earlier, to whom ECMO was not available, because hemodynamic stability resulted in a higher procedural success rate. ${ }^{51}$ In a similar cohort of 39 patients with shock and in whom death was otherwise certain, Fujimoto et al. achieved $44 \%$ in-hospital survival. ${ }^{52}$ 


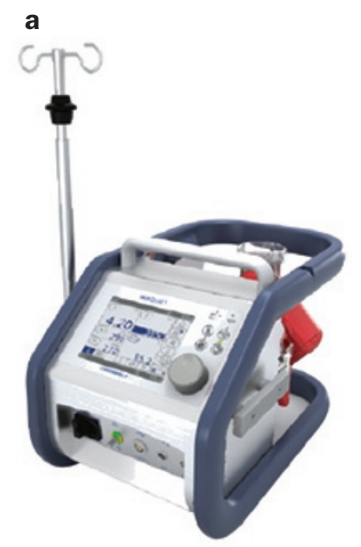

b

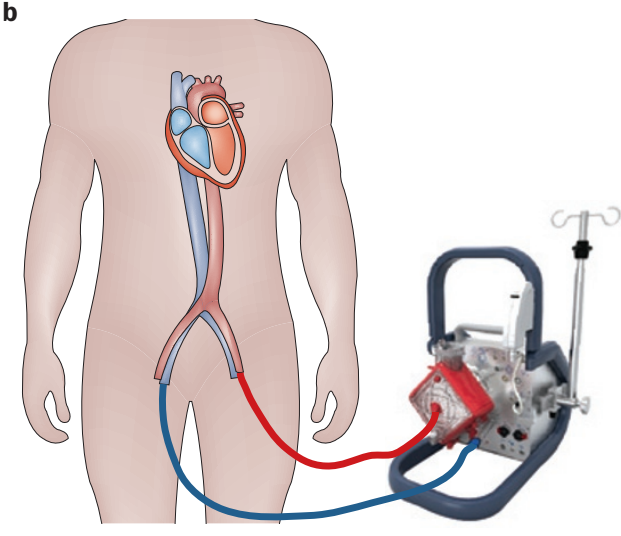

Figure 3 | The Maquet Cardiohelp ${ }^{\circledR}$ (Maquet Cardiopulmonary AG, Hirrlingen, Germany) hybrid pump oxygenator. a | The device is compact and easily portable, with a total weight of only $9 \mathrm{~kg}$. $\mathbf{b}$ | Veno-arterial extracorporeal membrane oxygenation (ECMO) is established by cannulation of a femoral vein and artery using the Seldinger technique. To expedite interhospital transfer these vessels can be located with guidewires before arrival of the outreach team. The cannulas can then be inserted rapidly to begin ECMO before transport by air or ground ambulance. Images of the Cardiohelp ${ }^{\circledR}$ device courtesy of $\odot$ Maquet Cardiopulmonary AG.

Several weeks of support with ECMO are feasible, after which pump flow is progressively reduced to $500 \mathrm{ml} / \mathrm{min}$ and then withdrawn. ECMO can provide an effective bridge to urgent cardiac transplantation or to prolonged LVAD support. In this context, Hoefer et al. performed ECMO as a bridge to a long-term LVAD with $50 \%$ 3-year survival, despite the fact that duration of support (1-10 days; mean 3 days) was limited by limb ischemia, bleeding, infection, thromboembolism, or pulmonary edema. ${ }^{53}$ Pagani and co-workers reported 43\% 1-year survival with ECMO in patients with cardiogenic shock complicated by cardiac arrest or severe hemodynamic instability. ${ }^{54}$ In another particularly high-risk group of 16 patients with left main stem occlusion, Yamauchi et al. performed PPCI with IABP and ECMO support and achieved overall $37.5 \%$ survival. ${ }^{55}$ Six patients were weaned from ECMO and discharged, three required a long-term LVAD and eight patients died. None of the patients for whom time to revascularization exceeded $4 \mathrm{~h}$ or who needed ECMO for $>3$ days survived.

Russo et al. described the use of the Centrimag ${ }^{\circledR}$ (Levitronix, Waltham, MA, USA) pump (discussed below) together with the Quadrox ${ }^{\circledR}$ (Maquet Cardiopulmonary AG, Hirrlingen, Germany) oxygenator for venoarterial ECMO in 15 patients with profound cardiogenic shock. ${ }^{56}$ Mean duration of ECMO support was $11.5 \pm 8.1$ days (range 1-30 days) and flows up to 5.21/min were achieved. Distal limb perfusion was guaranteed by cannulating both femoral artery and vein with $6 \mathrm{~mm}$ right-angled soft balloon-tipped coronary cannulas. Heparinized saline was infused into the venous system every $2 \mathrm{~h}$. A remarkable $80 \%$ of patients were weaned from ECMO or bridged to longer-term LVAD support or transplantation. Half of the patients who would otherwise have died, were discharged from hospital. ${ }^{56}$

In 2001, Formica et al. described a German out-reach system in which a dedicated ground ambulance is used to transport patients with cardiogenic shock from a district hospital to tertiary-care center. ${ }^{57}$ This group used the Rotaflow $^{\circledast}$ (Maquet Cardiopulmonary AG, Hirrlingen Germany) centrifugal pump together with a Quadrox ${ }^{\circledR}$ polymethil pentene oxygenator and heparin-coated circuit. The ECMO rescue team consisted of a cardiac surgeon, anesthetist, perfusionist, and intensive-care nurse. Femoral artery and venous cannulation were achieved with 15-17 French and 21-23 French cannulas, respectively, facilitated by cannulation of these vessels with the Seldinger technique by the local cardiologist before the arrival of the ECMO team. The mean time between request for help and start of ECMO was $126 \pm 30 \mathrm{~min}$. This approach was contraindicated when the patient was aged $>75$ years, had prolonged cardiac massage ( $>100 \mathrm{~min})$, or an unwitnessed cardiac arrest. Other contraindications were irreversible cerebral injury, active cancer, severe aortic regurgitation, or aortic dissection. Artl et al. have described a remarkable $62 \%$ recovery rate for outreach ECMO resuscitation of patients with myocardial infarction using portable hand-held circuits. ${ }^{58}$ On ECMO, gas exchange improved rapidly, vasopressor support was reduced, and signs of shock disappeared in all patients. Median time on ECMO support was 116h (range 5-168h) and the only significant difference between survivors and nonsurvivors was in $\mathrm{pH}$ value assessed before ECMO.$^{58}$ This report introduced the new Maquet Cardiohelp ${ }^{\circledR}$ (Maquet Cardiopulmonary AG, Hirrlingen, Germany) hybrid pump oxygenator unit with a total weight of only $9 \mathrm{~kg}$ (Figure 3). The system priming volume is $<600 \mathrm{ml}$ normal saline and, during transportation, the pump can function for $90 \mathrm{~min}$ independently of wall connections for oxygen or electricity.

\section{Surgically implanted blood pumps}

A variety of surgically implanted continuous-flow and pulsatile blood pumps have proven to be very effective postinfarction. ${ }^{59-61}$ The advantage of these devices is that central cannulation of atria, ventricles, and great arteries can bypass and unload the failing ventricle and provide blood flow of up to $101 / \mathrm{min}$. For left ventricular support, the ventricular assist device (VAD) drains the left atrium or ventricle and pumps blood into the aorta. For right ventricular bypass, the right atrium is normally used for VAD inflow with blood pumped into the main pulmonary artery, thereby avoiding peripheral vascular complications. Outcome depends on myocardial viability following revascularization, pre-existing left ventricular dysfunction, and potential for recovery in stunned or hibernating myocardium. In contrast to percutaneously inserted systems, all centrally implanted pumps can be kept in situ for periods ranging from weeks to several years. Temporary pumps can be replaced by long-term implanted LVADs if the native heart does not recover.

Data from the US INTERMACS ${ }^{62}$ provides important insights into the overall success of blood pumps in cardiogenic shock. In 2009, shock (status I) accounted for $42 \%$ of 483 VAD implants and, not surprisingly, these patients had a worse survival profile than those who underwent elective destination therapy. Patients who only required 
left ventricular support had the best outlook (50\% survival at 12 months). When biventricular support was needed, survival fell to $35 \%$ (Figure 4). Prognosis was poor for those receiving isolated right ventricular support or a total artificial heart. ${ }^{62}$ The registry only included patients who received devices approved by the FDA before 2009, which does not include the Centrimag ${ }^{\circledR}$ device or some of the new long-term rotary blood pumps.

\section{Temporary blood pumps}

The CentriMag ${ }^{\circledR}$ ventricular assist system employs a magnetically levitated rotor spinning at 500-5,500 rpm to generate up to $101 / \mathrm{min}$ of blood flow. The device has no mechanical bearings and no contact between the rotor and pump housing, ${ }^{63}$ which eliminates wear on the equipment and results in very low levels of hemolysis or thrombus formation. Patients are usually heparinized to provide an activated clotting time of $>200$ s; however, many patients on circulatory support have already undergone thrombolysis or are receiving clopidogrel or glycoprotein IIb/IIIa inhibitors and are at risk of postoperative bleeding that can prove refractory to correction of coagulopathy. Immediately after surgery, heparin can safely be withheld for 48-72 $\mathrm{h}$ until all mediastinal bleeding resolves. Provided that the flow rate is maintained at $>41 / \mathrm{min}$, the risks of thrombus formation or thromboembolism are negligible and no antiplatelet agents are required. The pump can be used safely for at least 30 days and, in many cases, for much longer. As implant numbers $(>5,000$ units to date) and confidence in device reliability increase, support durations of up to 3 months have been described in patients awaiting cardiac transplantation. ${ }^{59}$ The system is suitable for both left and right heart support and has been used in patients of all body sizes, including infants with myocardial infarction caused by congenital anomalous left coronary artery from the pulmonary artery. Flow measurement is digitally displayed on the device controller and, once in place, the system can be easily managed by trained nurses. Left ventricular unloading is very effective, particularly when the apex of the left ventricle is cannulated. For these reasons, this inexpensive, easy to use, and reliable system is now widely used throughout Europe and the USA.

John et al. reported on a seven-center US collaborative study in which 38 patients with cardiogenic shock were supported with the CentriMag ${ }^{\circledR}$ device for 1-60 days (mean 13 days). ${ }^{64}$ Survival at 30 days after weaning and pump explant was $47 \%$. For patients with postinfarction shock, the mean duration of support was 17 days (range 1-60 days) with $50 \%$ survival to hospital discharge and $43 \%$ 6-month survival. For patients who required biventricular support, the mean duration of therapy was 15 days, with $44 \%$ survival to explantation. ${ }^{64}$ In a salvage and bridgeto-decision experience at a transplant center, Haj-Yahia et al. reported a remarkable $80 \%$ survival at 30 days after Centrimag ${ }^{\oplus}$ implantation with a mean duration of support of almost 50 days. $^{65}$

The need for prolonged postinfarction support (weeks rather than days) is evident from the literature. Anderson et al. analyzed US registry data from 40

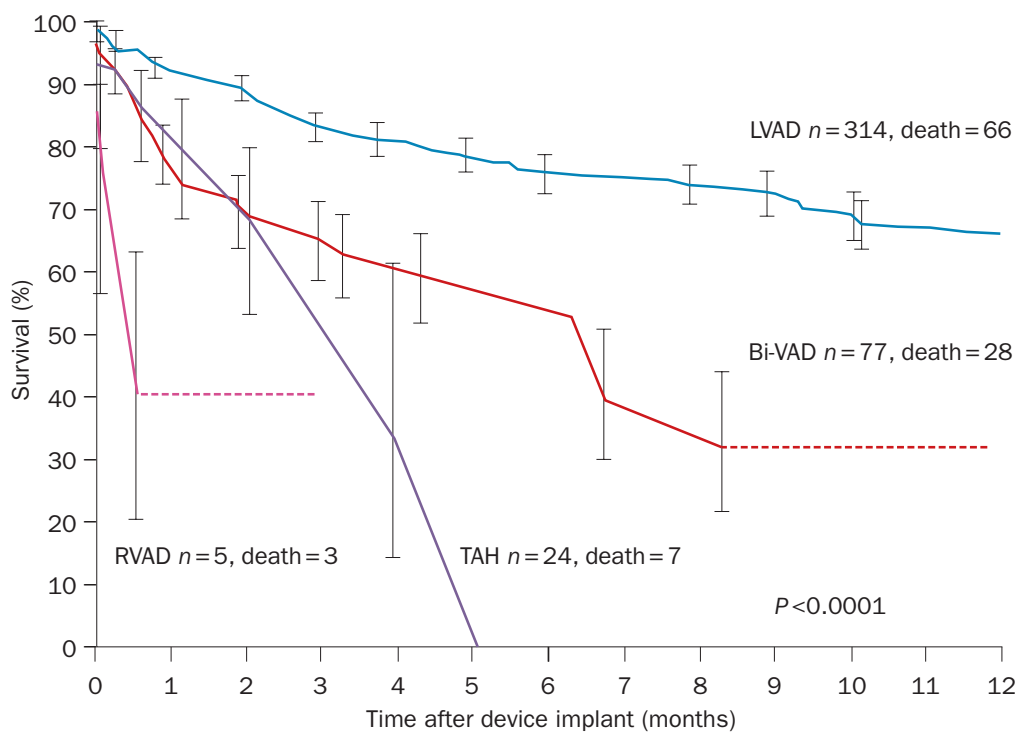

Figure 4 | Interagency Registry for Mechanically Assisted Circulatory Support survival data for 2006-2008. The need for right ventricular support or a total artificial heart was significantly associated with lower survival than for patients supported with an $\operatorname{LVAD}(P<0.0001)$. Modified from Journal of the American College of Surgeons, 208(5), INTERMACS: Interval Analysis of Registry Data. Holman, W. L. et al. 755-761, (C) (2009) with permission from Elsevier and the American College of Surgeons. Abbreviations: Bi-VAD, biventricular assist device; LVAD, left ventricular assist device; $n$, number of patients; RVAD, right ventricular assist device; TAH, total artificial heart.

centers for the Abiomed AB5000 (Danvers, MA, USA) external pulsatile system, reporting the outcome for the first 100 patients to receive this device for postinfarction shock. ${ }^{66}$ The $\mathrm{AB} 500^{\mathrm{mit}}$ paracorporeal ventricle is driven by a pneumatic console that allows for patient ambulation and delivers up to $61 / \mathrm{min}$ of blood flow. The newest console (AB Portable Driver"m; Abiomed Inc.) offers patient discharge capability. Left heart cannulation is achieved through the left atrium or ventricular apex, delivering blood to the ascending aorta. Right heart support is via the right atrium and pulmonary artery. Anticoagulation is with heparin to maintain an activated clotting time of $180-200 \mathrm{~s}$, or a partial thromboplastin time of 1.5-2.0 times control values. In this high-risk series, $93 \%$ and $5 \%$ of patients had undergone PPCI and thrombolysis, respectively. Urgent VAD implantation during cardiac arrest was required in $7 \%$, and $44 \%$ had undergone cardiac massage for an average of $20 \mathrm{~min}$. Duration of shock before circulatory support was initiated was $>24 \mathrm{~h}$ in $52 \%$ of patients, with a mean time from onset of shock to VAD implantation of $26.5 \mathrm{~h}$ (range 1-318 h). Only $24 \%$ of patients underwent device implantation within $<12 \mathrm{~h}$. Left or right ventricular support alone was used in $47 \%$ and $8 \%$ of patients, respectively, whereas $45 \%$ were judged to require biventricular support. Elevated central venous pressure in the presence of low systemic perfusion pressure was a reliable predictor of severe right ventricular dysfunction and need for a right VAD. All patients received high-dose inotropes, $91 \%$ had an IABP, $82 \%$ were on a ventilator, and $71 \%$ manifested ventricular tachycardia or ventricular fibrillation. Half of patients had a bilirubin level of $>1.5 \mathrm{mg} / \mathrm{dl}$ and $45 \%$ a creatinine level of $>1.8 \mathrm{mg} / \mathrm{dl}$. 

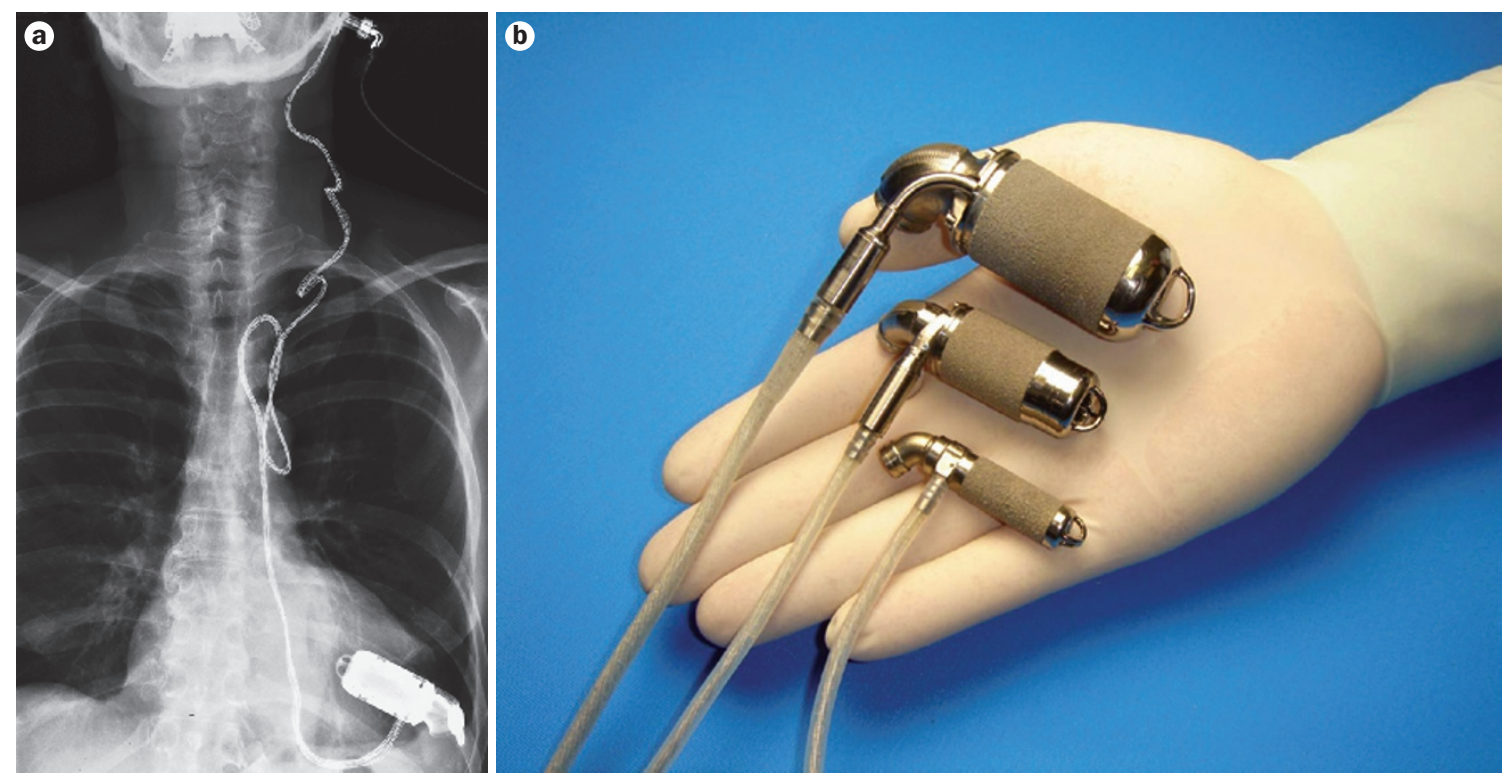

Figure 5 | The Jarvik $200{ }^{\circledR}$ 'Flowmaker' (Jarvik, New York, NY, USA) left ventricular assist device. a | Plain chest X-ray of a patient supported by the Jarvik $2000^{\circledR}$ 'Flowmaker' implanted into the apex of the left ventricle with outflow to the descending thoracic aorta. Skull pedestal power delivery is used. b | Range of Jarvik $2000^{\circledR}$ blood pumps, from the contemporary adult pump (largest) to the children's and infant's models (smallest), which are undergoing preclinical testing.

Despite the critical nature of this patient cohort, 30-day survival was $40 \%$, and $63 \%$ of survivors recovered native heart function. Transplant was performed in $20 \%$ of patients, and $17 \%$ underwent implantation of a longterm VAD. ${ }^{66}$ Notably, the duration of support required for recovery was $25 \pm 22$ days, ${ }^{66}$ which puts into context the failure of very short-term percutaneous LVADs to improve survival in comparative trials with the IABP. ${ }^{23}$

Leshnower et al. performed a retrospective review of patients with postinfarction cardiogenic shock treated at the Hospital of the University of Pennsylvania, PA, USA. ${ }^{61}$ This group employed the AbioMed BVS $5000^{\circledR}$ external pneumatic pulsatile (the predecessor of the AB5000) system for patients with body surface area $<1.8 \mathrm{~m}^{2}$. For larger patients, the pneumatically driven Thoratec external pulsatile system or, subsequently, the implanted HeartMate $^{\circledR}$ (Thoratec Corporation, Pleasanton, CA, USA) vented electric LVAD were employed. The latter involved coring of a tunnel in the ventricular apex often through infarcted myocardium. The mean age of patients was $54 \pm 11$ years and $43 \%$ had undergone previous CABG surgery. The mean time from acute myocardial infarction to LVAD implantation was 6.4 days. Biventricular support was required in $39 \%$ of patients, and $31 \%$ required renal dialysis; $88 \%$ were already receiving IABP support. Notably, in this series the LVAD inflow cannula was positioned in the apex of the failing left ventricle despite the fact that myocardial infarction had occurred within the previous few days. The mean duration of support was $56 \pm 54$ days (range 4-208 days) and 74\% of patients were successfully bridged to cardiac transplantation. With an in-hospital survival rate of $67 \%$, the authors reasonably concluded that early LVAD implantation with direct left ventricular cannulation was both safe and effective and should be standard therapy for this critically high risk group. ${ }^{61}$
In support of this strategy, Dang et al. showed that patients with acute anterior wall myocardial infarction and shock had improved survival at 6 and 12 months when early salvage LVAD implantation was undertaken before attempted revascularization by CABG surgery. ${ }^{67}$ These investigators showed that direct left ventricular cannulation provided superior cardiac decompression with better LVAD inflow and reduced risk of stroke when compared with left atrial cannulation. Effective decompression of the infarcted ventricle appeared to reduce the risk of tearing at the cannulation site and intraoperative bleeding. ${ }^{67}$ Other groups have used both the pneumatic HeartMate $^{\circledR}$ 1000IP and the electric HeartMate ${ }^{\circledR}$ XVE devices in patients with acute myocardial infarction with impressive bridge-to-transplant outcomes. ${ }^{68,69}$ These findings refute the argument that direct left ventricular cannulation is unsafe after infarction and open the door to early use of long-term rotary blood pumps in this setting.

Outcomes of patients undergoing LVAD support are critically dependent on adequate right ventricular function, which must provide sufficient transpulmonary flow to fill the LVAD. The pathophysiology of acute ischemic right heart failure is complex. ${ }^{70}$ Factors other than right ventricular infarction include afterload increase (secondary pulmonary hypertension or hypoxic pulmonary vasoconstriction), cytokine-induced decreases in systolic and diastolic ventricular function, and ventricular arrhythmias. Right ventricular failure reduces LVAD filling and output, increases venous congestion, and decreases perfusion to vital organs. ${ }^{71}$ Even a nonischemic right ventricle can be negatively influenced by a shift of the intraventricular septum and impaired filling. Right ventricular failure is more likely in severely ill patients and increases mortality. ${ }^{72}$ Patients with central venous pressure approaching left atrial pressure $(>20 \mathrm{mmHg}$ ) before LVAD implantation 

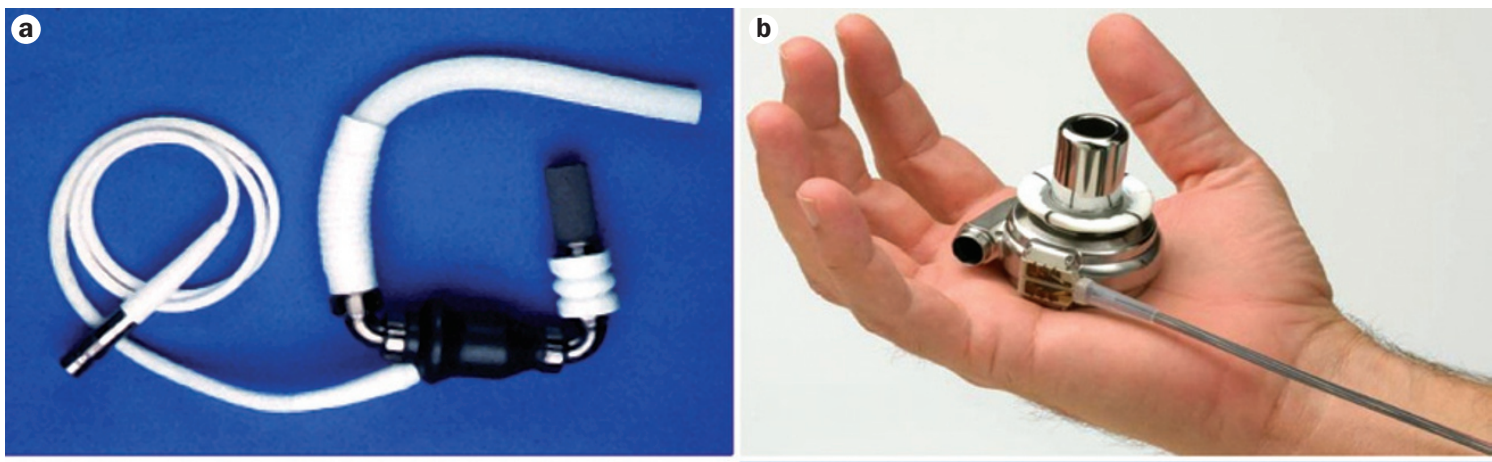

C
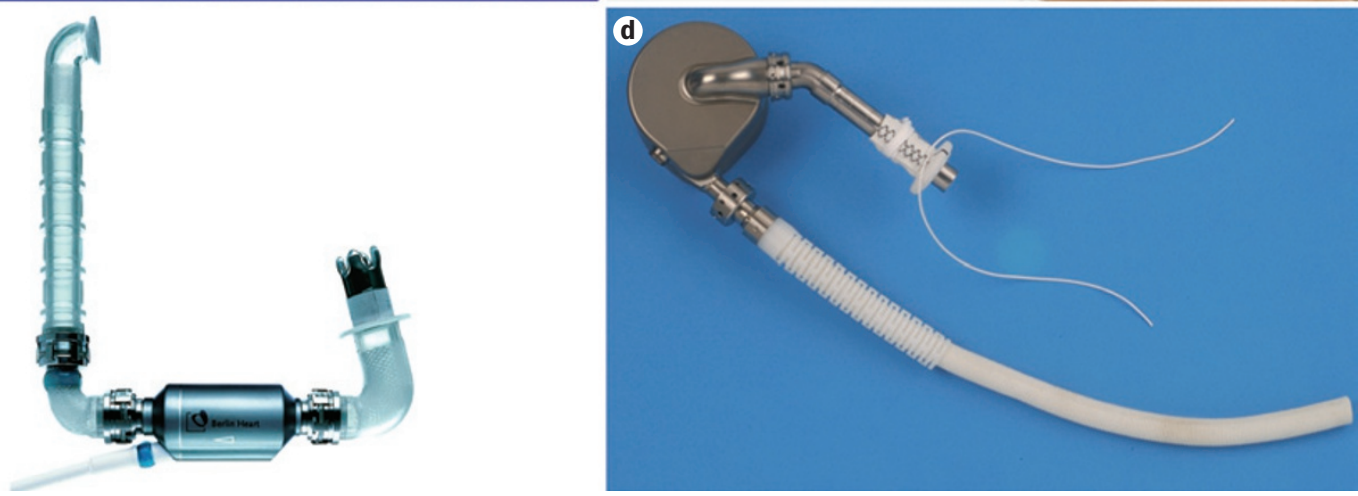

Figure 6 | Fully implantable rotary blood pumps. a | HeartMate ${ }^{\circledR}$ II (Thoratec Corporation, Pleasanton, CA, USA). b | HeartWare ${ }^{\circledR}$ (Miami Lakes, FL, USA). c | Incor (Berlin Heart, Berlin, Germany). d | DuraHeart ${ }^{\circledast}$ (Terumo Corporation, Shibuya-ku, Japan).

seem to be at highest risk. ${ }^{72}$ Preoperative optimization by reducing blood volume before LVAD implantation can help protect the right ventricle, as can pharmacological reduction of pulmonary vascular resistance. Need for mechanical right-sided support portends poor survival, but outcomes are better if biventricular support is established simultaneously. ${ }^{73}$ Delay in initiating right-sided support is associated with worsening organ congestion and failure to resolve multiorgan failure. ${ }^{72}$ In practice, few patients with salvageable myocardial infarction develop right ventricular dysfunction that is unresponsive to inotropic support with or without IABP and a pulmonary vasodilator. ${ }^{70}$

\section{Long-term rotary blood pumps}

For the past 10 years, fully implantable, long-term rotary blood pumps have been used in patients with cardiogenic shock, but only after initial stabilization and reversal of multiorgan failure with a temporary VAD or ECMO. These pumps are designed to be mechanically durable for at least 5 years, with correspondingly low levels of hemolysis or risk of thromboembolism. Whether axial or centrifugal in design, they have a single moving part, the impeller, which provides $5-101 / \mathrm{min}$ of continuous blood flow without pulse pressure. Continuous flow is well tolerated in the long term, and the control and power systems are easily portable. ${ }^{74}$ Most patients regain pulse pressure when the native left ventricle is unloaded and contractility improves. Mechanical reliability and quality of life are improved and complication rates are reduced in comparison with volume displacement LVADs. ${ }^{75}$ However, these devices cost UK£60,000-80,000, which is considerably more than a temporary blood pump $(£ 5,000-10,000)$.
Economic rationale, therefore, dictates that long-term rotary blood pumps should not be used primarily for patients who have little chance of survival, although they have been used in such patients in the past.

To date, the longest duration of event-free survival (7.5 years) has been reported for a patient with a Jarvik $2000^{\circledR}$ 'Flowmaker' (Jarvik, New York, NY, USA) and this pump showed little evidence of mechanical wear or thrombus formation when explanted following noncardiacrelated death ${ }^{76}$ (Figure 5). Other devices, including the HeartMate $^{\circledR}$ II, HeartWare ${ }^{\circledR}$ (Miami Lakes, FL, USA), Incor $^{\circledR}$ (Berlin Heart, Berlin, Germany), and DuraHeart ${ }^{\circledR}$ (Terumo Corporation, Shibuya-ku, Japan) VADs (Figure 6) are in widespread use and all demonstrate excellent mechanical reliability ${ }^{77-79}$ Thromboembolism is the main risk associated with these devices, but has been limited by improved pump design and anticoagulant regimes. Survival exceeding 5 years is now found reproducibly with rotary blood pumps and perhaps justifies their cost.

With the progressive decline in the number of available donor hearts and a gradual improvement in implantable blood-pump technology, the rescue strategies for cardiogenic shock are changing. ${ }^{80}$ Bridge to a long-term LVAD is a more-realistic option than bridge to transplant for most patients. Consequently, management of other cardiac lesions (including high-grade coronary occlusion) becomes an issue. Understandable reticence to complicate LVAD implantation in the high-risk patient exists, but uncorrected aortic or tricuspid regurgitation are problematic. Functional tricuspid regurgitation can be dynamic and responsive to medical therapy. Stretching of the mural annulus is the dominant mechanism. Gross tricuspid 


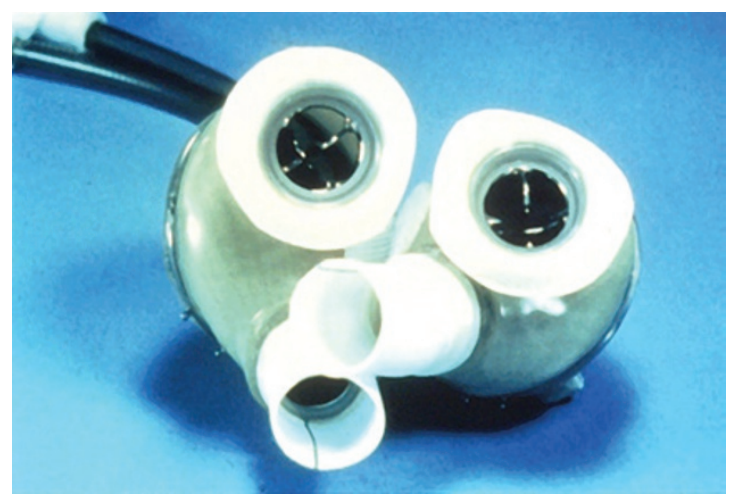

Figure 7 | The CardioWest ${ }^{\mathrm{TM}}$ total artificial heart (SynCardia Systems, Inc., Tucson, AZ, USA).

regurgitation, secondary to pulmonary hypertension, can recur, even after weeks of diuretic therapy have rendered the condition mild. Thus, maintaining liberal indications for tricuspid valve repair at the time of LVAD implantation is important. ${ }^{81}$ When the right ventricle fails, increased diastolic pressure causes septal shift and compression of the left ventricle, which can impair LVAD filling. The LVAD itself reduces left ventricular volume and may exacerbate tricuspid regurgitation acutely because of leftward shift of the interventricular septum and increased venous return. Even when the LVAD reduces pulmonary artery pressure, tricuspid regurgitation tends to be progressive in the long term and will limit cardiac output. Mortality during LVAD implantation does not seem to be increased by concomitant tricuspid annuloplasty, as it is with aortic valve replacement or more extensive interventions. ${ }^{82}$

\section{The total artificial heart}

Use of a total artificial heart as a bridge to transplantation after myocardial infarction remains controversial and impractical for most health-care systems. However, no satisfactory alternative exists for patients with massive catastrophic myocardial infarction or chronic left ventricular failure followed by acute right ventricular infarction. ${ }^{83}$ The survival rate for the total artificial heart appears to be more than double that for separate LVAD and RVAD deployment. ${ }^{81}$ The CardioWest $^{\mathrm{Tm}}$ total artificial heart (SynCardia Systems, Inc., Tucson, AZ, USA) was approved by the FDA in October 2004 and provides rapid complete hemodynamic restoration with blood flow exceeding $91 / \mathrm{min}$ (Figure 7). ${ }^{84}$ With a portable external pump driver, patients with the total artificial heart can live at home while waiting for a transplant. However, the device can only be fitted in patients with body surface area $>1.7 \mathrm{~m}^{2}$ and is only used for bridge to cardiac transplantation when surgical exploration suggests that the heart will not recover with isolated left ventricular support using cardiopulmonary bypass. The native heart is then excised with transection through the right and left atria, aorta, and pulmonary arteries, as for cardiac transplantation. The pulsatile prosthetic ventricles-either pneumatically or electrically driven - are sewn into place and activated. The patient is then weaned from the heart-lung machine.
In practice, very few total artificial hearts are used. In a single-center experience from France, of 42 patients who received a CardioWest ${ }^{\text {Tix }}$ total artificial heart over 16 years, around half received the device for shock as a result of ischemic cardiomyopathy. ${ }^{85}$ Duration of support was 1-292 days (mean $101 \pm 86$ days) and 30 patients (72\%) survived to cardiac transplantation, with $90 \%$ and $76 \%$ survival at 1 and 10 years, respectively. Stroke was rare (7\%), but $85 \%$ of all patients developed complications associated with infection. ${ }^{85}$ Copeland et al. reported data from a five-center prospective study of the CardioWest ${ }^{\mathrm{m}}$ heart to test safety and efficacy in 81 transplant-eligible patients at risk of imminent death, of whom 65 (79\%) survived to cardiac transplant. ${ }^{84}$ Of 35 control patients who met trial entry criteria, but did not receive the device, only $46 \%$ survived to transplant. Survival at 12 months was $70 \%$ in bridged patients compared with $31 \%$ among controls. The mean time from artificial heart implantation to transplantation was 79 days. By contrast, patients who did not receive a device underwent urgent transplant at a mean of only 8.5 days. Ten patients $(12.3 \%)$ with the CardioWest ${ }^{\mathrm{TM}}$ heart experienced a stroke and 15 (18.5\%) had other neurological problems. One serious device malfunction caused death at 124 days postimplantation.

\section{Managing low peripheral vascular resistance}

In cardiogenic shock, and for patients who are receiving mechanical circulatory support, end-organ perfusion is critically dependant on systemic blood pressure and peripheral vascular resistance. Both the cytokine response after myocardial infarction and the systemic inflammatory response to cardiopulmonary bypass (after LVAD implantation, urgent coronary bypass, or septal defect repair) can trigger vasodilatory shock and lactic acidosis. ${ }^{86}$ Vasodilatory inotropes, such as milrinone, contribute to loss of vascular tone, and even multiple catecholamine vasopressors (norepinephrine, epinephrine) prove an ineffective antidote. Catecholamines cause vasoconstriction by opening voltage-gated channels that allow calcium influx into the smooth muscle cell, thereby increasing the cytoplasmic calcium content. This mechanism promotes coupling of actin and myosin causing smooth muscle contraction in the vessel wall and vasoconstriction. However, in vasodilatory shock with lactic acidosis secondary to hypoperfusion, this mechanism fails and catecholamines become ineffective vasoconstrictors. ${ }^{87}$ Failure of this therapy probably occurs because acidosis opens ATPsensitive potassium channels in myocytes, allowing efflux of potassium and hyperpolarization, ${ }^{88}$ preventing voltage-gated calcium channels from opening and halting calcium influx into the myocyte. ${ }^{89}$ The catecholamine vasoconstrictor mechanism is thus interrupted, rendering these agents ineffective in vasodilatory shock. At the same time, shock promotes endothelial production of the vasodilator nitric oxide (NO) whose action is unaffected by catecholamines. ${ }^{90}$

In 1997, Argenziano and the group from New YorkPresbyterian Hospital, NY, USA showed that patients with vasodilatory shock after LVAD implantation had low levels of autologous arginine vasopressin, and that 
shock resolved when these individuals were given intravous vasopressin. ${ }^{91}$ Notably, vasopressin does not increase blood pressure in normotensive patients, which suggests that this hormone functions through a mechanism different to that of other vasoconstrictors. ${ }^{92}$ When vasopressin binds to its vascular receptor, three pathways are activated. First, the second-messenger system of inositol triphosphate and diacyl-glycerol is it activated in vascular smooth muscle cells causing a rise in cytoplasmic calcium, ${ }^{93}$ promoting contraction of the actin and myosin filaments and vasoconstriction. Second, vasopressin inhibits NO-induced accumulation of cyclic GMP in vascular smooth muscle cells, preventing the vasodilatory effect of NO. ${ }^{94}$ Third, vasopressin closes potassium channels preventing the efflux of potassium and promoting myocyte depolarization, allowing calcium to enter the myocyte and cause contraction. ${ }^{95}$ In contrast to catecholamines, vasopressin has beneficial effects on renal function. ${ }^{95}$ Vasopressin receptors are concentrated in efferent arterioles and thereby increase filtration fraction, whereas catecholamine receptors are in the afferent arteriole so that vasoconstriction decreases filtration fraction. However, vasoconstriction in splanchnic vessels can compromise flow to the liver and gut.

The beneficial effects of vasopressin on blood pressure in patients with an LVAD is now well established. In 2000, the group from New York-Presbyterian Hospital reported their experience with 102 patients who underwent LVAD implantation between 1995 and 1998, 50 of whom received perioperative vasopressin infusion to treat mean arterial pressure $<60 \mathrm{mmHg}$, despite treatment with high-dose catecholamines. ${ }^{86}$ A low dose of vasopressin $(0.1 \mathrm{U} / \mathrm{min})$ significantly increased systemic vascular resistance and blood pressure (to a mean of $75 \mathrm{mmHg}$ ) and allowed catecholamine dosage to be reduced. This low dose of vasopressin has no effect on normotensive individuals, but restores appropriate physiological levels of vasopressin and blood pressure in patients with an LVAD. ${ }^{86}$ The authors suggest that prolonged or profound hypotension causes central nervous system depletion of vasopressin together with enhanced NO production and hyperpolarization of myocytes. ${ }^{86}$ With acquired resistance to catecholamines, the patient experiences profound vasodilatory hypotension, visceral hypoperfusion, and lactic acidosis. Exogenous vasopressin infusion restores physiological levels, allowing myocyte repolarization and inhibition of NO production. Catecholamine sensitivity is re-established and blood pressure rises. Moreover, in this cohort of patients, visceral, cardiac, and pulmonary perfusion was not compromised whereas renal failure improved markedly. ${ }^{86}$ As a result, vasopressin infusion now provides an important backup strategy for patients with cardiogenic shock where LVAD or biventricular VAD rescue is compromised by catecholamine-resistant profound hypotension.

\section{The way forward}

Despite the widespread adoption of PPCI, appropriate access to mechanical circulatory support does not exist for patients with cardiogenic shock in many countries. LVADs are expensive, but not scarce. In order to improve survival, patients with an unstable or deteriorating condition after myocardial infarction should be transferred urgently to a specialist center and managed by a multidisciplinary team of cardiologists, cardiac surgeons, and intensive-care specialists. ${ }^{96}$ The provision for IABP or ECMO support during transfer already exists and surgeons have a pivotal role in the management of high-risk cases. ${ }^{97}$ The value of specialized management was illustrated by El Banayosy et al. in Germany, who achieved 70\% survival at 30 days from 50 consecutive patients referred from surrounding district hospitals who received three high-dose inotropes with or without IABP therapy $9{ }^{96}$ For individuals in whom medical management with IABP counterpulsation could not sustain cardiac index $>2.41 / \mathrm{min} / \mathrm{m}^{2}$ and mean blood pressure $>60 \mathrm{mmHg}$, a VAD was used within $6 \mathrm{~h}$ of arrival and early efforts were made to identify those who were eligible for transplant. In practice, manipulation of medical therapy accounted for the greatest proportion of those who survived to 30 days. Patients who required urgent LVAD implantation had high mortality unless they later underwent cardiac transplantation.

Outcomes of permanent LVAD implantation are unsatisfactory in patients with established multisystem organ failure. ${ }^{2}$ Given the uncertainty about the recovery of these patients, a clear role exists for inexpensive temporary support postinfarction, pending a decision about longterm therapy. ${ }^{63,65}$ This support should be easy to initiate and provide physiological levels of blood flow so that neurological status can be assessed as other organs recover. Prognosis is best for those who can be weaned from the blood pump and survive to hospital discharge. Should left ventricular function prove inadequate, switch to a longterm implantable LVAD can provide several years of goodquality life and does not preclude cardiac transplantation for the small cohort who fit eligibility criteria. ${ }^{63,98}$

Discrepancies in access to care are widely recognized and underpinned by demographic parameters. Joyce et al. reviewed data from the 2002 and 2003 US Nationwide Inpatient Sample to explore the fate of 297,866 patients admitted with congestive heart failure. ${ }^{99}$ Inclusion of patients with postinfarction cardiogenic shock in this study resulted in overall mortality of $45 \%$. Multivariate logistic regression analysis showed that age was one of the strongest predictors of whether a patient would receive an LVAD. Patients aged $<65$ years were seven-times more likely to receive an LVAD than those aged $\geq 65$ years. White patients were three-to-four-times more likely than black patients, and males were two-to-three-times more likely than females, to undergo LVAD implantation (all $P<0.001$ ). Patients admitted to an academic hospital were 6.4-times more likely to receive an LVAD than those admitted to a private hospital. Comorbid disease also negatively influenced decisions regarding long term LVAD therapy. During the study period, a total of 51 US hospitals were certified for LVAD destination therapy, yet only $0.1 \%$ of patients with advanced heart failure received a device. ${ }^{99}$

Provision of tertiary care may now have a precedent in law. The European Convention on Human Rights places certain obligations on all public authorities, including health-care systems. Article 2 defines "the right to life and 
a positive duty on medical staff and organizations to preserve life and palliate distressing symptoms" ${ }^{100}$ This ruling is now pivotal when reaching decisions about very sick patients and when defining health-care policy in Europe. As a result, the UK General Medical Council have issued new guidelines for end-of-life care, which clearly apply to patients with acute or chronic heart failure. ${ }^{100}$ These guidelines state that "the terminally ill must be offered high-quality treatment to support them to live as well as possible until death." ${ }^{100}$ The presumption exists that all reasonable steps will be taken to prolong life if a satisfactory solution exists and is based on contemporary evidence of effectiveness and risks. Importantly, in relation to LVADs, the General Medical Council states that "you should not withhold a treatment if doing so would involve significant risk for the patient and the only justification is resource contraints." 100 Thus, failure to intervene in a patient who has the potential to recover could now be deemed neglectful or, frankly, negligent. Mechanical circulatory support should now be regarded as equivalent to hemodialysis for renal failure. Hospital costs are similar when distributed over time. In Europe, the threshold values for cost-effectiveness allow up to $€ 5,000$ for each month of survival gained or for each quality-adjusted month gained. ${ }^{101,102}$ Annual thresholds are generally set at approximately $€ 50,000-100,000$ or $£ 25,000-30,000$. The cost of reperfusion together with mechanical bridge to recovery should remain within these thresholds.

One of the main issues underpinning failure to intervene in patients with postinfarction cardiogenic shock is that LVADs have largely been limited to cardiac transplant centers and patients who are overtly not eligible for transplant (that is, those aged $>65$ years) are not referred to these hospitals. Equally, a bridge-to-transplant strategy is futile given the large numbers of critically ill patients with shock and the few available donor hearts, which are appropriately directed to more-stable patients with heart failure. ${ }^{103}$ Both temporary and long-term circulatory support devices must be made available in regional cardiac centers at which other types of nontransplant heart failure surgery is undertaken. ${ }^{104}$ This approach is already endorsed in the USA, where regulatory guidelines are established. The International Society for Heart and Lung Transplantation (ISHLT) acknowledged that all cardiac surgical centers should be equipped with temporary devices for postcardiotomy or post-PPCI salvage. ${ }^{104}$ Long-term support with an electively implanted rotary blood pump is then a relatively small step should the heart not recover. The conclusion of the Board of ISHLT was that destination therapy programs should not be restricted to transplant centers, but established where heart failure teams expressed an interest. These departments can establish a comprehensive 'hub and spoke' access scheme for postinfarction shock. ${ }^{105}$ Consequently, new rotary blood pumps will have an increasing role in patients with impaired left ventricular function who do not respond to revascularization. Technology continues to improve and an aggressive approach may eventually prevent more deaths in this common condition.

\section{Conclusions}

Mechanical circulatory support can sustain life during profound postinfarction cardiogenic shock and is an important adjunct to coronary angioplasty in rapidly deteriorating patients. Neither the IABP nor percutaneously inserted LVADs have been shown to improve survival in established cardiogenic shock. By contrast, both ECMO and centrally implanted blood pumps show the capacity to salvage more than half of those patients who would otherwise die. Three outcomes are possible after hemodynamic stabilization; the best is functional recovery, after which long-term prognosis is good and free from heart failure in most cases. Next is inadequate recovery, necessitating the implantation of a long-term LVAD. Evidence suggests that an LVAD can be safely inserted into the apex of the left ventricle only days after STEMI. Last, for selected patients, there is the possibility of urgent cardiac transplantation. However, the lack of available donor hearts precludes this route for most patients. For those resuscitated from cardiac arrest, temporary circulatory support gives time to assess cerebral injury.

Cardiac surgeons and perfusionists are an important component of the 'shock team'. Consequently 'Heart Attack Centers' would be best located in tertiary-care cardiac centers. No precedent has been set for LVAD use being restricted to transplant centers. Access to circulatory support is an important issue that has not been resolved in cardiogenic shock, and will only improve when devices and expertise become readily available.

Review criteria
This Review covers a rapidly evolving field where
prospective, randomized trials are unusual. A
comprehensive list of original articles was obtained
from the PubMed database using the search terms
"myocardial infarction”, "cardiogenic shock”, "circulatory
support", "intra-aortic balloon pump", "extracorporeal
membrane oxygenation", and "left ventricular assist
device”. All papers were in the English language,
although reports published in Asian countries were also
scrutinized. In addition, the reference lists of identified
articles were reviewed.

1. Mullens, W. et al. Importance of venous congestion for worsening of renal function in advanced decompensated heart failure. J. Am. Coll. Cardiol. 53, 589-596 (2009).

2. Rose, E. A. et al. Long-term use of a left ventricular assist device for end-stage heart failure. N. Engl. J. Med. 345, 1435-1443 (2001).

3. Thiele, H., Allam, B., Chatellier, G., Schuler, G. \& Lafont, A. shock in acute myocardial infarction: the Cape Horn for trials? Eur. Heart J. 31, 1828-1835 (2010).

4. Arzamendi, D. et al. New insights into the management of cardiogenic shock complicating myocardial infarction: role of urgent heart transplantation. J. Heart Lung Transplant. 27, 984-989 (2008).

5. Krishnamani, R., DeNofrio, D. \& Konstam, M. A. Emerging ventricular assist devices for long-term cardiac support. Nat. Rev. Cardiol. 7, 71-76 (2010).

6. Reynolds, H. R. \& Hochman, J. S. Cardiogenic shock: current concepts and improving outcomes. Circulation 117, 686-697 (2008).

7. Just, P. M. et al. Reimbursement and economic factors influencing dialysis modality choice around the world. Nephrol. Dial. Tranpslant. 23, 2365-2373 (2008). 
8. Thiele, H. \& Schuler, G. Cardiogenic shock: to pump or not to pump? Eur. Heart J. 30, 389-390 (2009).

9. Kolyva, C., Pantalos, G. M., Pepper, J. R. \& Kuis, A. W. How much of the intra-aortic balloon pump volume is displaced toward the coronary circulation? J. Thorac. Cardiovasc. Surg. 140, 110-116 (2010)

10. Cohen, M. et al. Intra-aortic balloon counterpulsation in US and non-US centers: results of the Benchmark Registry. Eur. Heart J. 24, 1763-1770 (2003).

11. Van de Werf, F. et al. Management of acute myocardial infarction in patients presenting with ST-segment elevation. The Task Force on the Management of Acute Myocardial Infarction of the European Society of Cardiology. Eur. Heart J. 24, 28-66 (2003).

12. Ryan, T. J. et al. 1999 update: ACC/AHA guidelines for the management of patients with acute myocardial infarction. A report of the American College of Cardiology/American Heart Association Task Force on Practice Guidelines (Committee on Management of Acute Myocardia Infarction). J. Am. Coll. Cardiol. 34, 890-911 (1999).

13. Nordhaug, D., Steensrud, T., Muller, S. Husnes, K. V. \& Myrmel, T. Intra-aortic balloon pumping improves hemodynamics and right ventricular efficiency in acute ischemic right ventricular failure. Ann. Thorac. Surg. 78, 1426-1432 (2004).

14. Yoshitani, H. et al. Effects of intra-aortic balloon counterpulsation on coronary pressure in patients with stenotic coronary arteries. Am. Heart J. 154, 725-731 (2007).

15. Katz, E. S., Tunick, P. A. \& Kronzon, I. Observations of coronary flow augmentation and balloon function during intra-aortic balloon counterpulsation using transesophageal echocardiography. Am. J. Cardiol. 69 1635-1639 (1992).

16. Bonios, M. J. et al. Increase in coronary blood flow by intra-aortic balloon counterpulsation in a porcine model of myocardial reperfusion. Int. J. Cardiol. 138, 253-260 (2010).

17. Westaby, S., Balacumaraswami, L. \& Sayeed, R. Maximising survival potential in very high risk cardiac surgery. Heart Fail. Clin. 3, 159-180 (2007).

18. Christenson, J. T. et al. Trends in intra-aortic balloon counterpulsation complications and outcomes in cardiac surgery. Ann. Thorac. Surg. 74, 1086-1090 (2002).

19. Hochman, J. S. et al. Cardiogenic shock complicating acute myocardial infarction etiologies, management and outcome: A report from the SHOCK trial registry. SHould we emergently revascularize Occluded Coronaries for cardiogenic shock? J. Am. Coll. Cardiol. 36, 1063-1070 (2000).

20. Barron, H. V. et al. The use of intra-aortic balloon counterpulsation in patients with cardiogenic shock complicating acute myocardial infarction: data from the National Registry of Myocardial Infarction 2. Am. Heart J. 141, 933-939 (2001).

21. Sjauw, K. D. et al. A systematic review and meta-analysis of intra-aortic balloon pump therapy in ST-elevation myocardial infarction: should we change the guidelines. Eur. Heart $\mathrm{J}$. 30, 459-468 (2009).

22. Ohman, E. M. \& Hochman, J. S. Aortic counterpulsation in acute myocardial infarction: physiologically important but does the patient benefit? Am. Heart J. 141, 889-892 (2001).

23. Cheng, J. M. et al. Percutaneous left ventricular assist devices vs intra-aortic balloon pump counterpulsation for treatment of cardiogenic shock: a meta analysis of controlled trials. Eur. Heart J. 30, 2102-2108 (2009).

24. Stone, G. W. et al. Role of cardiac surgery in the hospital phase management of patients treated with primary angioplasty for acute myocardial infarction. Am. J. Cardiol. 85, 1292-1296 (2000).

25. Morrow, D. A. et al. Concurrent evaluations of novel cardiac biomarkers in acute coronary syndrome: myeloperoxidase and soluble CD409 ligand and the risk of recurrent ischaemic events in TACTICS-TIMI 18. Eur. Heart J. 29, 1096-1102 (2008).

26. US National Institutes of Health. Intra-aortic Balloon Pump in Cardiogenic Shock II (IABP SHOCK II). ClinicalTrials.gov [online], http://clinicaltrials.gov/ct2/show/ NCT00491036 (2011).

27. Jeger, R. V. et al. Emergency early revascularization in patients with cardiogenic shock on admission: a report from the SHOCK trial and registry. Eur. Heart J. 27, 664-670 (2006).

28. Garcia-Alvarez, A. et al. Early risk stratification of patients with cardiogenic shock complicating acute myocardial infarction who undergo percutaneous coronary intervention. Am. J. Cardiol. 103, 1073-1077 (2009).

29. Wong, S. C. et al. Angiographic findings and clinical correlates in patients with cardiogenic shock complicating acute myocardial infarction: a report from the SHOCK Trial registry. SHould we emergently revascularize Occluded Coronaries for cardiogenic shock? J. Am. Coll. Cardiol. 36 (Suppl. A), 1077-1083 (2000)

31. Burkhoff, D., Cohen, H., Brunckhorst, C. \& O'Neill, W. W for the TandemHeart Investigators Group. A randomized multicenter clinical study to evaluate the safety and efficacy of the Tandem Heart percutaneous ventricular assist device versus conventional therapy with intra-aortic balloon pumping for treatment of cardiogenic shock. Am. Heart J. 152 469.e1-469.e8 (2006).

30. Dixon, S. R. et al. A prospective feasibility trial investigating the use of the Impella 2.5 system in patients undergoing high-risk percutaneous coronary intervention (the PROTECT 1 trial): initial US experience. JACC Cardiovasc. Interv. 2, 91-96 (2009).

32. Henriques, J. P. \& de Mol B. A. New percutaneous mechanical left ventricular support for acute MI: the AMC MACH program. Nat. Clin. Pract. Cardiovasc. Med. 5, 62-63 (2008).

33. Theile, H. et al. Randomized comparison of intra-aortic balloon pump support with a percutaneous left ventricular assist device in patients with revascularized acute myocardial infarction complicated by cardiogenic shock. Eur. Heart J. 26, 1276-1283 (2005).

34. Meyns, B., Stolinski, J., Leunens, V., Verbeten, E. \& Flameng, W. Left ventricular support by catheter mounted axial flow pump reduces infarct size. J. Am. Coll. Cardiol. 41, 1087-1095 (2003).

35. Sjauw, K. D. et al. Left ventricular unloading in acute ST-segment elevation myocardial infarction patients is safe and feasible and provides acute and sustained left ventricular recovery. J. Am. Coll. Cardiol. 51, 1044-1046 (2008).

36. Sjauw, K. D. et al. Supported high-risk percutaneous coronary interventions with the Impella 2.5 device: the Europella registry. J. Am. Coll. Cardiol. 54, 2430-2434 (2009).

37. Lamarche, Y. et al. Comparative outcomes in cardiogenic shock patients managed with
Impella microaxial pump or extracorporeal life support. J. Thorac. Cardiovasc. Surg. 142, 60-65 (2011).

38. Seyfarth, M. et al. A randomized clinical trial to evaluate the safety and efficacy of a percutaneous left ventricular assist device versus intra-aortic balloon pumping for treatment of cardiogenic shock caused by myocardial infarction. J. Am. Coll. Cardiol. 52, 1584-1588 (2008).

39. Thiele, H. et al. Reversal of cardiogenic shock by percutaneous left atrial-to-femoral arterial bypass assistance. Circulation 104, 2917-2922 (2001).

40. Kar, B., Gregoric, I. D., Basra, S. S., Idelchick, G. M. \& Loyalka, P. The percutaneous ventricular assist device in severe refractory cardiogenic shock. J. Am. Coll. Cardiol. 57, 688-696 (2011).

41. Hochman, J. S. et al. Early revascularization in acute myocardial infarction complicated by cardiogenic shock. SHOCK Investigators. Should we emergently revascularize occluded coronaries for cardiogenic shock. N. Engl. J. Med. 341, 625-634 (1999).

42. Kohsaka, S. et al. Systemic inflammatory response syndrome after acute myocardial infarction complicated by cardiogenic shock. Arch. Intern. Med. 165, 1643-1650 (2005).

43. Vranckx, P. et al. The Tandem Heart percutaneous trans-septal left ventricular assist device: a safeguard in high-risk percutaneous coronary interventions. The six year Rotterdam experience. Eurolntervention 4, 331-337 (2008).

44. Mahmoudi, M., Syed, A. I. \& Waksman, R. The role of percutaneous circulatory assist devices in acute myocardial infarction and high-risk percutaneous intervention in the $21^{\text {st }}$ century. Cardiovasc. Revasc. Med. 12, 237-242 (2011)

45. Al-Husami, W. et al. Single-center experience with the Tandem Heart percutaneous ventricular assist device to support patients undergoing high risk percutaneous coronary intervention. J. Invasive Cardiol. 20, 319-322 (2008)

46. Smedira, N. G. et al. Clinical experience with 202 adults receiving extracorporeal membrane oxygenation for cardiac failure: survival at five years. J. Thorac. Cardiovasc. Sug. 122, 92-102 (2001)

47. Massetti, M. et al. Back from irreversibility: extracorporeal life support for prolonged cardiac arrest. Ann. Thorac. Surg. 79, 178-183 (2005).

48. Feindt, P. et al. Use of extracorporeal circulation (ECC) outside the cardiac operating room: indications, requirements and recommendations for routine practice. Thorac. Cardiovasc. Surg. 59, 66-68 (2011).

49. Avalli, L. et al. Percutaneous left heart decompression during extracorporeal membrane oxygenation: an alternative to surgical and transeptal venting in adult patients. ASAIO J. 57, 38-40 (2011).

50. Schmid, C., Philipp, A., Mueller, T. \& Hilker, M. Extracorporeal life support-systems, indications, and limitations. Thorac. Cardiovasc. Surg. 57, 449-454 (2009).

51. Sheu, J. T. et al. Early extracorporeal membrane oxygenator-assisted primary percutaneous coronary intervention improved 30-day clinical outcomes in patients with ST-segment elevation myocardial infarction complicated with profound cardiogenic shock. Crit. Care Med. 38 , 1810-1817 (2010).

52. Fujimoto, K. et al. Percutaneous extracorporeal life support for treatment of fatal mechanical complications associated with acute myocardial infarction. Artif. Organs 25, 1000-1003 (2001). 
53. Hoefer, D. et al. Outcome evaluation of bridge-to-bridge concept in patients with cardiogenic shock. Ann. Thorac. Surg. 82, 28-33 (2006).

54. Pagani, F. D., Aaronson, K. D., Swaniker, F. \& Bartlett, R. H. The use of extracorporeal life support in adult patients with primary cardiac failure as a bridge to implantable left ventricular assist device. Ann. Thorac. Surg. 71, 77-81 (2001).

55. Yamauchi, T., Masai, T., Takeda, K., Kainuma, A. \& Sawa, Y. Percutaneous cardiopulmonary support after acute myocardial infarction at the left main trunk. Ann. Thorac. Cardiovasc. Surg. 15, 93-97 (2009).

56. Russo, C. F. et al. Veno-arterial extracorporeal membrane oxygenation using Levitronix centrifugal pump as bridge to decision for refractory cardiogenic shock. J. Thorac. Cardiovasc. Surg. 140, 1416-1421 (2010).

57. Formica, F., Avalli, L., Redaelli, G. \& Paolini, G. Interhospital stabilisation of adult patients with refractory cardiogenic shock by veno-arterial extracorporeal membrane oxygenation. Int. J. Cardiol. 147, 164-165 (2011).

58. Artl, M. et al. First experience with a new miniaturised life support system for mobile percuatneous cardiopulmonary bypass. Resuscitation 77, 345-350 (2008).

59. Slaughter, M. S. et al. Results of a multicenter trial with the Thoratec implantable ventricular assist device. J. Thorac. Cardiovasc. Surg. 133, 1573-1580 (2007).

60. Gray, L. A. Jr. \& Champsaur, G. G. The BVS 5000 biventricular assist device. The worldwide registry experience. ASAIO J. 40, M460-M464 (1994).

61. Leshnower, B. G. et al. Safety and efficacy of left ventricular assist device support in postmyocardial infarction cardiogenic shock. Ann. Thorac. Surg. 81, 1365-1370 (2006).

62. Holman, W. L. et al. INTERMACS: interval analysis of registry data. J. Am. Coll. Surg. 208, 755-761 (2009).

63. John, R. et al. Experience with the Levitronix CentriMag circulatory support system as bridge to decision in patients with refractory cardiogenic shock and multisystem organ failure. J. Thorac. Cardiovasc. Surg. 134, 351-358 (2007).

64. John, R. et al. Outcomes of a multicenter trial of the Levitronix CentriMag ventricular assist system for short-term circulatory support. J. Thorac. Cardiovasc. Surg. 141, 932-939 (2010).

65. Haj-Yahia, S. et al. Bridging patients after salvage from bridge to decision directly to transplant by means of prolonged support with the CentriMag short-term centrifugal pump. J. Thorac. Cardiovasc. Surg. 138, 227-230 (2009).

66. Anderson, M. et al. Use of the AB 5000 ventricular assist device in cardiogenic shock after acute myocardial infarction. Ann. Thorac. Surg. 90, 706-712 (2010).

67. Dang, N. C. et al. Left ventricular assist device implantation after acute anterior wall myocardial infarction and cardiogenic shock: a two-center study. J. Thorac. Cardiovasc. Surg. 130, 693-698 (2005).

68. Tayara, W. et al. Improved survival after acute myocardial infarction complicated by cardiogenic shock with circulatory support and transplantation: comparing aggressive intervention with conservative treatment. J. Heart Lung Transplant. 25, 504-509 (2006)

69. Park, S. J., Nguyen, D. Q., Bank, A. J. Ormaza, S. \& Bolman, R. M. $3^{\text {rd }}$ Left ventricular assist device bridge therapy for acute myocardial infarction. Ann. Thorac. Surg. 69, 1146-1151 (2000).
70. Lahm, T. et al. Medical and surgical treatment of acute right ventricular failure. J. Am. Coll. Cardiol. 56, 1435-1446 (2010).

71. Ochiai, Y. et al. Predictors of severe right ventricular failure after implantable left ventricular assist device insertion: analysis of 245 patients. Circulation 106 (Suppl. I), |198-I202 (2002).

72. Morgan, J. A. et al. Is severe right ventricular failure in left ventricular assist device recipients a risk factor for unsuccessful bridging to transplant and post-transplant mortality? Ann. Thorac. Surg. 77, 859-863 (2004)

73. Fitzpatrick, J. R. $3^{\text {rd. }}$ et al. Early planned institution of biventricular mechanical circulatory support results in improved outcomes compared with delayed conversion of a left ventricular assist device to a biventricular assist device. J. Thorac. Cardiovasc. Surg. 137, 971-977 (2009).

74. Saito, S., Nishinaka, T. \& Westaby, S. Hemodynamics of chronic non pulsatile flow: implications for LVAD development. Surg. Clin. North Am. 84, 61-74 (2004).

75. Slaughter, M. S. et al. Advanced heart failure treated with a continuous-flow left ventricular assist device. N. Engl. J. Med. 361, 2241-2251 (2009).

76. Westaby, S. et al. Destination therapy with a rotary blood pump and novel power delivery. Eur. J. Cardiothorac. Surg. 37, 350-356 (2010).

77. Hetzer, R. et al. First experiences with a novel magnetically suspended axial flow left ventricular assist device. Eur. J. Cardiothorac. Surg. 25, 964-970 (2004).

78. Strueber, M. et al. Multicenter evaluation of an intrapericardial left ventricular assist system. J. Am. Coll. Cardiol. 57, 1375-1382 (2011).

79. Morshuis, M. et al. European experience of DuraHeart magnetically levitated centrifugal left ventricular assist system. Eur. J. Cardiothorac. Surg. 35, 1020-1027 (2009).

80. MacGowan, G. A., Parry, G., Schueler, S. \& Hasan, A. The decline in heart transplantation in the UK. BMJ 342, d2483 (2011).

81. Westaby, S. Editorial comment. Tricuspid regurgitation in left ventricular assist device patients. Eur. J. Cardiothorac. Surg. http:// dx.doi.org/10.1016/j.ejcts.2011.06.019.

82. Pal, J. D. et al. Low operative mortality with implantation of a continuous-flow left ventricular assist device and impact of concurrent cardiac procedures. Circulation 120, S215-S219 (2009).

83. Slepian, M. J. \& Copeland, J. G. The total artificial heart in refractory cardiogenic shock: saving the patient versus saving the heart. Nat. Clin. Pract. Cardiovasc. Med. 5, 64-65 (2008).

84. Copeland, J. G. et al. Cardiac replacement with a total artificial heart as a bridge to transplantation. N. Engl. J. Med. 351, 859-867 (2004).

85. Roussel, J. C. et al. CardioWest (Jarvik) total artificial heart: a single center experience with 42 patients. Ann. Thorac. Surg. 87, 124-130 (2009).

86. Morales, D. L. et al. Arginine vasopressin in the treatment of 50 patients with postcardiotomy vasodilatory shock. Ann. Thorac. Surg. 69, 102-106 (2000).

87. Thiemermann, C., Szabó, C., Mitchell, J. A. \& Vane, J. R. Vascular hyporeactivity to vasoconstrictor agents and hemodynamic decompensation in hemorrhagic shock is mediated by nitric oxide. Proc. Natl Acad. Sci. USA 90, 267-271 (1993).
88. Landry, D. W. \& Oliver, J. A. The ATP-sensitive $\mathrm{K}^{+}$ channel mediates hypotension in endotoxemia and hypoxic lactic acidosis in dog. J. Clin. Invest. 89, 2071-2074 (1992).

89. Szabó C. \& Salzman, A. L. Inhibition of ATPactivated potassium channels exerts pressor effects and improves survival in a rat model of severe hemorrhagic shock. Shock 5, 391-394 (1996).

90. Cotter, G. et al. LINCS: L-NAME (a No Synthase inhibitor) in the treatment of refractory cardiogenic shock: a prospective randomized study. Eur. Heart J. 24, 1287-1295 (2003).

91. Argenziano, M. et al. A prospective randomized trial of arginine vasopressin in the treatment of vasodilatory shock after left ventricular assist device placement. Circulation 96 (Suppl. 9), II286-II290 (1997)

92. Braunwald, E. \& Wagner, H. N. Jr. The pressor effect of the antidiuretic principle of the posterior pituitary in orthostatic hypotension. J. Clin. Invest. 35, 1412-1418 (1956).

93. Howel, J. \& Wheatley, M. Molecular pharmacology of V1a vasopressin receptors. Gen. Pharmacol. 26, 1143-1152 (1995).

94. Kusano, E. et al. Arginine vasopressin inhibits interleukin-1 beta-stimulated nitric oxide and cyclic guanosine monophosphate production via the $\mathrm{V} 1$ receptor in cultured rat vascular smooth muscle cells. J. Hypertens. 15, 627-632 (1997).

95. Edwards, R. M., Rinza, W. \& Kinter, L. B. Renal microvascular effects of vasopressin and vasopressin antagonist. Am. J. Physiol. 256 (2 Pt 2), F274-F278 (1989).

96. El-Banayosy, A. et al. A multidisciplinary network to save the lives of severe persistent cardiogenic shock patients. Ann. Thorac. Surg. 80, 543-547 (2005).

97. Foley, D. S. et al. A review of 100 patients transported on extracorporeal life support. ASAIO J. 48, 612-619 (2002)

98. Aggarwal, S. \& Pagani, F. D. Bridge to transplantation: current outcomes. J. Card. Surg. 25, 455-461 (2010).

99. Joyce, D. L., Conte, J. V., Russell, S. D. Joyce, L. D. \& Chang, D. C. Disparities in access to left ventricular assist device therapy. J. Surg. Res. 152, 111-117 (2009).

100. General Medical Council. Treatment and care towards the end of life: good practice in decision making [online], www.gmc-uk.org/ End of life.pdf 32486688.pdf (2010).

101. Messori, A. et al. Left ventricular assist device as destination therapy: application of the payment by results approach for the device reimbursement. J. Thorac. Cardiovasc. Surg. 138, 480-485 (2009).

102. Pearson, S. D., Rawlins, M. D. Quality, innovation and value for money - NICE and the British National Heath Service. JAMA 294, 2618-2622 (2005).

103. MacGowan, G. A., Parry, G., Schueler, S. $\&$ Hasan, A. The decline in heart transplantation in the UK. BMJ 342, d2483 (2011).

104. Westaby, S. Lifetime circulatory support must not be limited to transplant centers. Heart Fail. Clin. 3, 369-375 (2007).

105. Kherani, A. R. et al. Implantation of a left ventricular assist device and the hub-and-spoke system in treating acute cardiogenic shock: who survives? J. Thorac. Cardiovasc. Surg. 126, 1634-1635 (2003)

Author contributions

S. Westaby researched data for and wrote the article. All authors contributed to the discussion of content and reviewed the manuscript prior to submission. 